\title{
FUTURE CLIMATE UNCERTAINTY AND SPATIAL VARIABILITY OVER TAMILNADU STATE, INDIA
}

\section{RAJALAKSHMI D. JAGANNATHAN R. GEETHALAKSHMI V.}

Received: $29 / 09 / 2014$

Accepted: 31/03/2015

Available online: 01/04/2015

\author{
Agro Climate Research Centre, Tamil Nadu Agricultural University
}

Coimbatore-641003, Tamilnadu, India

*to whom all correspondence should be addressed: e-mail: rajiamt@yahoo.in

\section{ABSTRACT}

The present study analyses future climate uncertainty for the 21st century over Tamilnadu state for six weather parameters: solar radiation, maximum temperature, minimum temperature, relative humidity, wind speed and rainfall. The climate projection data was dynamically downscaled using high resolution regional climate models, PRECIS and RegCM4 at $0.22^{\circ} \times 0.22^{\circ}$ resolution. PRECIS RCM was driven by HadCM3Q ensembles (HQ0, HQ1, HQ3, HQ16) lateral boundary conditions (LBCs) and RegCM4 driven by ECHAM5 LBCs for 130 years (1971-2100). The deviations in weather variables between the end century (2071-2100) and the base years (1971-2000) were calculated for all grids of Tamilnadu for ascertaining the uncertainty. These deviations indicated that all model members projected no appreciable difference in relative humidity, wind speed and solar radiation. The temperature (maximum and minimum) however showed a definite increasing trend with 1.7 to $3.7^{\circ} \mathrm{C}$ and 1.9 to $4.3^{\circ} \mathrm{C}$, respectively. The model members for rainfall exhibited a high uncertainty as they projected high negative and positive deviations (-325 to $784 \mathrm{~mm}$ ). The spatial representation of maximum and minimum temperature indicated a definite rhythm of increment from coastal area to inland. However, variability in projected rainfall was noticed.

Keywords: Climate uncertainty, PRECIS, RegCM4, A1B scenario, Tamilnadu

\section{Introduction}

The change in climate is not certain and has been widely discussed in both public and scientific society as it has influence on various activities. In order to ascertain its impact and to workout adaptation and mitigation strategies, we need to know the change that could happen in future. The General Circulation Models (GCMs) plays a major role in predicting the future climate. As these GCMs do not provide sufficient information on finer scale as required for impact studies by different sectors, Regional Climate Model (RCM) are generally employed for getting fine scale outputs of a region using the GCM output. The uncertainty in the projected data could affect the usability of impact assessment studies. In general, uncertainty is a debate about the level of certainty needed to reach a firm conclusion and it is a perennial issue in science (Schneider and Duriseti, 2002). In order for these data to be reliable, an uncertainty analysis is required.

Common approach to analyse uncertainty is to use past climate change to constrain the future climate change. An alternate approach is to simply use ensembles of models to provide a range of probable future climate without reference to observations (e.g. as it has happened in the Third Assessment Report (TAR) of the IPCC to provide the range of future warming (Cubasch et al., 2001). 
One of the primary techniques employed in uncertainty analysis is the sensitivity analysis (Smith, 2002). This usually gives a range of possible outcomes. To overcome these uncertainties instead of using single model results, it is better to consider results from a range of coupled models. Perturbed physics approach is highly useful to quantify variability within the model but it cannot capture intermodel variability. The combination of both the intermodel and intramodel variability can be used for further impact assessment studies. In the present study future climate uncertainty at the end of 21st century was quantified over Tamilnadu state of India along with the spatial variability of climate.

\section{Methods}

\subsection{Study location}

The uncertainties in climate projections was studied for the state of Tamilnadu, which is geographically located between $8.07^{\circ} \mathrm{N}$ to $13.57^{\circ} \mathrm{N}$ latitude and $76.24^{\circ} \mathrm{E}$ to $80.35^{\circ} \mathrm{E}$ longitude for the period of 130 years from 1971-2100.

\subsection{Climate projection scenario}

For this study A1B scenario was selected as it is considered suitable for India's economic growth and technological interventions. The A1B emission scenario falls under A1 storyline that describes a future world of very rapid economic growth, global population that peaks in mid-century and declines thereafter, and the rapid introduction of new and more efficient technologies and this assuming that energy flow is balanced across all sources which takes into account fossil and non-fossil energy.

\subsection{Regional Climate Models and lateral boundaries}

PRECIS (Providing REGional Climate for Impact Studies) and RegCM4 (Regional Climate Model version 4) were used to downscale the future projections. In particular, the PRECIS model was obtained from Hadley Centre, UK Met office, which was run using $\operatorname{HadCM} 3$ (Q0, Q1, Q3 and Q16) ensembles as Lateral Boundary Conditions (LBCs). RegCM4 developed by International Centre for Theoretical Physics, Italy was used with EH5OM GCM output. Both RCMs were run at $25 \mathrm{~km}$ grid resolution under A1B scenario. The domain was selected to cover up to Central India (Fig. 1, 2). The data were then retrieved for Tamilnadu (Fig. 3) State that covered 220 grid points in PRECIS and 218 grid points in RegCM4.

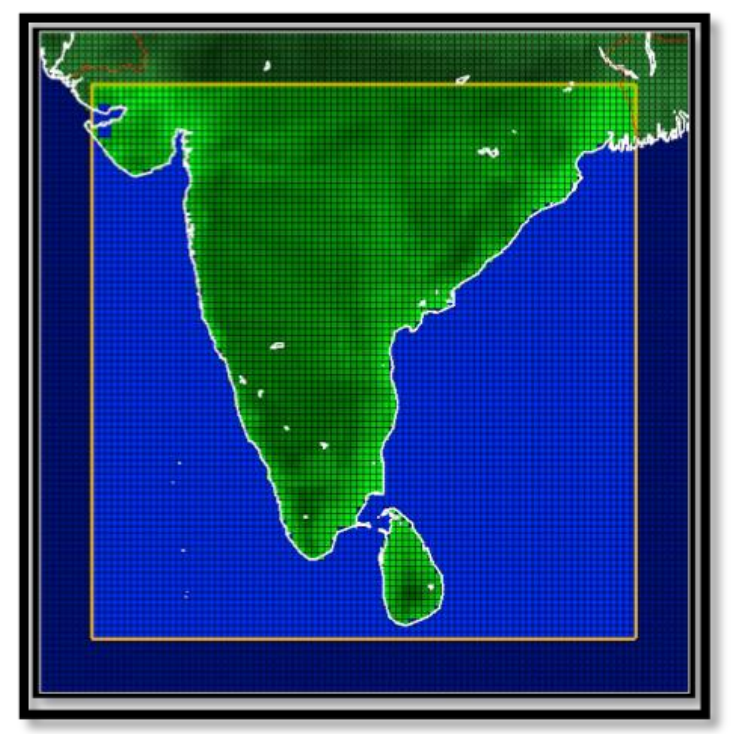

Figure 1. PRECIS domain

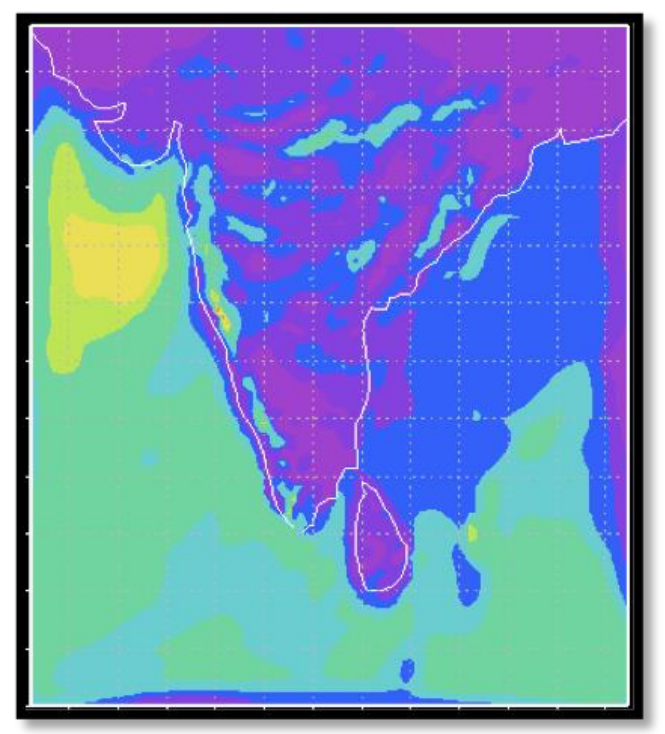

Figure 2. RegCM4 domain 


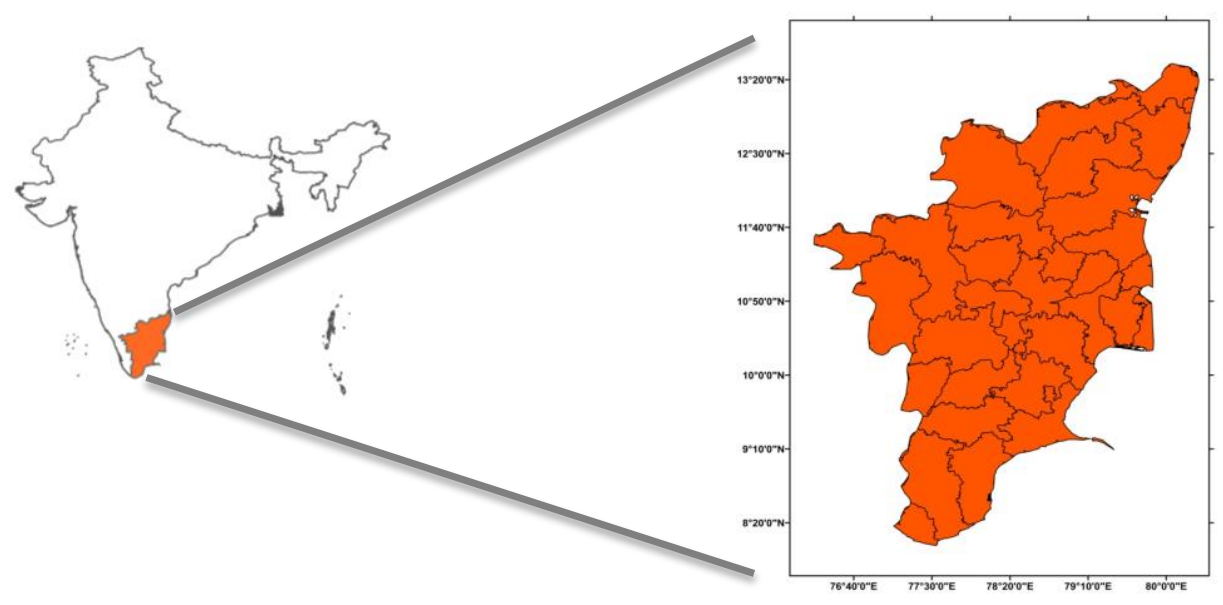

Figure 3. Tamilnadu (study area)

\subsection{Verification of climate data}

Verification of climate data was done using the Climate Research Unit (CRU) data of University of East Anglia, UK prepares observed monthly climatology at a resolution of $0.5^{\circ} \times 0.5^{\circ}$ over the globe. The British Atmospheric Data Centre hosts the current version of CRU data (CRU_TS3.1). The same was downloaded in ASCll format and used as observed climatology for evaluating the simulation from RCMs. The error statistics like bias, root mean square error (RMSE) along with correlation coefficient $(r)$ and index of agreement (Willmott, 1981) (d) were estimated for prediction against CRU gridded observation. The $25 \mathrm{~km}$ resolution model outputs were interpolated to the CRU $0.5 \times 0.5$ degree grids using NCL 'natgrid' function and comparisons were made on grid-to-grid basis for the monthly and annual time series data.

\subsection{Uncertainty in climate projection}

Uncertainty in climate projections were obtained from the runs of PRECIS ensembles and RegCM4 Regional Climate Model (RCM) for A1B scenario. The daily output of the members (PRECIS ensembles and RegCM4) were converted to decadal, using Perl programme. To obtain the uncertainty at the end of the century, the deviations from base year were calculated by obtaining the difference between the end century (2071-2100) and base years (1971-2000). Though, there would exist variation for every decade, to access the climate change uncertainty at the end of 21st century, the deviation was worked out for the end century to that of base years to give an overview of climate at the end of the 21st century to make decisions. The deviations were calculated for every grids (PRECIS: 220 grids; RegCM4: 218 grids) in both the models and then the maximum, minimum and average of all grid points were taken using excel spreadsheet. These ranges of maximum, minimum and average are given as uncertainty in climate projections.

\subsection{Spatial variability}

Spatial variability was analysed for PRECIS HQO and RegCM4 members as they have shown high reliability compared to other members using ArcGIS 9.3. The parameter-wise results obtained are presented below.

\section{Results}

\subsection{Verification of model results}

The output (maximum temperature, minimum temperature and rainfall) from five simulations one from REG driven by the boundaries of ECHAM5 GCM and four from PRECIS RCM driven by perturbed physics ensembles of HadCM3Q (HQ0, HQ1, HQ3 \& HQ16) for the period 1971-2000 were compared with Climate Research Unit (CRU) gridded observations for the same period and the results are presented below. 


\subsection{Simulation of maximum temperature}

The model-wise mean monthly climatology along with CRU observations are furnished in Table 1 . The overall mean CRU observed maximum temperature for the 30 year study period (1971- 2000) is $32{ }^{\circ} \mathrm{C}$ while the simulations by models showed variability in the level of $-0.9^{\circ} \mathrm{C}$ to $3.1^{\circ} \mathrm{C}$. The REG, though under estimated the maximum temperature was very close to $\mathrm{CRU}$ observations $\left(31.1^{\circ} \mathrm{C}\right)$, while all the PRECIS simulations $\left(\mathrm{HQO}\left(33.2^{\circ} \mathrm{C}\right), \mathrm{HQ} 1\left(34.2^{\circ} \mathrm{C}\right), \mathrm{HQ} 3\left(34.0^{\circ} \mathrm{C}\right)\right.$ \& $\left.\mathrm{HQ} 16\left(35.1^{\circ} \mathrm{C}\right)\right)$ overestimated the mean daily maximum temperature.

Table 1. CRU observed and model simulated mean monthly maximum temperature $\left({ }^{\circ} \mathrm{C}\right)$ of Tamilnadu with trend (1971-2000).

\begin{tabular}{ccccccccccccccc}
\hline Models & Jan & Feb & Mar & Apr & May & Jun & Jul & Aug & Sep & Oct & Nov & Dec & Mean & Trend \\
\hline CRU & 29.6 & 31.4 & 33.3 & 34.7 & 35.1 & 33.5 & 32.5 & 32.1 & 32.1 & 31.0 & 29.6 & 28.8 & 32.0 & 1.07 \\
\hline HQ0 & 29.6 & 32.5 & 35.8 & 38.2 & 38.5 & 35.6 & 34.2 & 33.5 & 33.5 & 30.5 & 28.2 & 28.3 & 33.2 & 0.35 \\
\hline HQ1 & 31.5 & 34.0 & 36.7 & 38.5 & 39.0 & 36.2 & 34.7 & 34.5 & 34.6 & 31.0 & 29.8 & 30.2 & 34.2 & -0.19 \\
\hline HQ3 & 31.0 & 33.5 & 36.6 & 38.4 & 39.1 & 37.4 & 34.8 & 34.5 & 33.4 & 30.3 & 29.4 & 29.8 & 34.0 & -0.33 \\
\hline HQ16 & 31.4 & 34.2 & 36.9 & 39.3 & 40.9 & 37.8 & 36.6 & 35.6 & 35.9 & 32.7 & 29.9 & 30.3 & 35.1 & 0.67 \\
\hline REG & 28.4 & 31.1 & 34.2 & 36.2 & 35.7 & 30.8 & 30.0 & 30.2 & 30.7 & 30.0 & 28.3 & 27.8 & 31.1 & 0.01
\end{tabular}

The pattern of observation for different months by CRU was well simulated by different models, however there is a difference between the hottest and coldest months. In CRU observation, December $\left(28.8^{\circ} \mathrm{C}\right)$ was the coldest month, which was simulated by REG while all PRECIS runs, estimated the lowest maximum temperature only during November. However, the REG failed to simulate the highest maximum temperature in May recorded by CRU while all PRECIS runs simulated it during May with warm bias. The PRECIS runs HQ1 (-0.0064) and HQ3 (-0.0111) showed a negative trend for the study period of 1971-2000 in simulating maximum temperature while all other runs showed a positive trend.

Results of error and agreement statistics (Table 2) for different models in comparison with CRU observation revealed a negative bias for REG (-0.8 monthly and -0.8 annual), while it is positive for all PRECIS runs. The test of significance for correlation between CRU observed and model simulation, indicated a high significant correlation (0.01) for both annual and monthly climatology. The lowest RMSE was observed in REG (2.1 monthly and 1.3 annual) simulation while the highest index of agreement (d) was obtained for PRECIS HQO (0.66 monthly and 0.76 annual) run.

Table 2. Error and agreement statistics for maximum temperature between model simulations and CRU observation (1971-2000).

\begin{tabular}{ccccccccc}
\hline \multirow{2}{*}{ Models } & \multicolumn{2}{c}{ Bias } & \multicolumn{2}{c}{ r2 } & \multicolumn{2}{c}{ RMSE } & \multicolumn{2}{c}{ d } \\
\cline { 2 - 10 } & Monthly & Annual & Monthly & Annual & Monthly & Annual & Monthly & Annual \\
\hline HQ0 & 1.0 & 1.0 & 0.58 & 0.63 & 2.5 & 1.6 & 0.66 & 0.76 \\
HQ1 & 1.9 & 1.9 & 0.50 & 0.58 & 2.9 & 2.4 & 0.60 & 0.62 \\
HQ3 & 1.7 & 1.7 & 0.53 & 0.57 & 2.8 & 2.2 & 0.62 & 0.64 \\
HQ16 & 2.8 & 2.8 & 0.50 & 0.50 & 3.4 & 3.1 & 0.54 & 0.47 \\
REG & -0.8 & -0.8 & 0.43 & 0.54 & 2.1 & 1.3 & 0.65 & 0.75 \\
\hline
\end{tabular}

\subsection{Simulation of minimum temperature}

The results for CRU observed and model simulated mean monthly minimum temperature with its trend is furnished in Table 3. The cycle of observation by CRU was well captured by all the models over different months. The variation in the overall mean daily minimum temperature between CRU and simulations ranged from $-3.2^{\circ} \mathrm{C}$ to $1.0^{\circ} \mathrm{C}$. As observed under maximum temperature, the HQ1 $(-0.0069)$ also showed a negative trend for minimum temperature while remaining runs simulated positive trend. However, there exists variation between them in simulating the trend which ranged from $0.23{ }^{\circ} \mathrm{C}$ to $0.92{ }^{\circ} \mathrm{C}$ for the study period (1971-2000) while the CRU observation showed only $0.56{ }^{\circ} \mathrm{C}$. 
Table 3. CRU observed and model simulated mean monthly minimum temperature $\left({ }^{\circ} \mathrm{C}\right)$ of Tamilnadu with trend (1971-2000).

\begin{tabular}{ccccccccccccccc}
\hline Models & Jan & Feb & Mar & Apr & May & Jun & Jul & Aug & Sep & Oct & Nov & Dec & Mean & Trend \\
\hline CRU & 20.0 & 21.0 & 22.6 & 25.0 & 25.2 & 24.6 & 24.0 & 23.6 & 23.5 & 22.9 & 21.9 & 20.8 & 22.9 & 0.56 \\
HQ0 & 18.8 & 19.1 & 21.7 & 24.5 & 25.6 & 25.0 & 24.4 & 24.0 & 23.3 & 21.9 & 20.6 & 19.5 & 22.4 & 0.41 \\
HQ1 & 17.8 & 18.8 & 21.7 & 24.4 & 25.5 & 24.9 & 24.3 & 24.0 & 23.5 & 23.6 & 19.4 & 18.0 & 22.2 & -0.21 \\
HQ3 & 17.8 & 19.1 & 22.0 & 24.4 & 25.6 & 25.3 & 24.4 & 24.0 & 23.1 & 21.4 & 19.4 & 18.2 & 22.1 & 0.23 \\
HQ16 & 20.1 & 21.2 & 23.6 & 25.9 & 27.3 & 26.6 & 25.6 & 25.0 & 24.8 & 23.6 & 21.9 & 20.6 & 23.9 & 0.92 \\
REG & 16.7 & 16.5 & 18.6 & 20.9 & 21.8 & 21.6 & 21.3 & 21.0 & 20.6 & 20.2 & 19.4 & 17.7 & 19.7 & 0.31 \\
\hline
\end{tabular}

The error and agreement statistics for minimum temperature simulated by model compared to CRU observations are furnished in Table 4. All the simulations except HQ16 simulated a negative bias indicating under estimation by the models. There exists high significant correlation for all model simulations as seen from correlation coefficient values of monthly and annual comparisons. A higher RMSE was observed in REG (3.1 monthly and 3.1 annual) simulation while the PRECIS runs showed insignificant differences among them. The highest index of agreement for monthly (0.88) and annually (0.94) comparison was seen in PRECIS HQO simulation, while the lowest was observed in REG (0.59 monthly and 0.58 annual) simulation.

Table 4. Error and agreement statistics for minimum temperature between model simulations and CRU observation (1971-2000).

\begin{tabular}{ccccccccc}
\hline \multirow{2}{*}{ Models } & \multicolumn{2}{c}{ Bias } & \multicolumn{2}{c}{ r2 } & \multicolumn{2}{c}{ RMSE } & \multicolumn{2}{c}{ d } \\
\cline { 2 - 10 } & Monthly & Annual & Monthly & Annual & Monthly & Annual & Monthly & Annual \\
\hline HQ0 & -0.3 & -0.3 & 0.83 & 0.87 & 1.3 & 0.9 & 0.88 & 0.94 \\
HQ1 & -0.5 & -0.5 & 0.83 & 0.88 & 1.7 & 1.1 & 0.85 & 0.90 \\
HQ3 & -0.6 & -0.6 & 0.83 & 0.88 & 1.5 & 1.0 & 0.85 & 0.92 \\
HQ16 & 1.1 & 1.1 & 0.85 & 0.90 & 1.6 & 1.3 & 0.83 & 0.87 \\
REG & -3.0 & -3.0 & 0.77 & 0.83 & 3.1 & 3.1 & 0.59 & 0.58 \\
\hline
\end{tabular}

\subsection{Simulation of Rainfall}

The mean monthly rainfall for the study period (1971-2000) along with its trends are furnished in Table 5. The simulation of all models showed a high variability in their estimation of rainfall compared to the temperatures. The REG showed over estimation to the level of 25 per cent, while HQ1 showed nearly 50 per cent under estimation. The remaining PRECIS runs produced only under estimated Rainfall. However, all the PRECIS runs were able to capture the highest rainfall cycle during northeast monsoon period (OND) while the REG failed to capture the same as it produced more rainfall during southwest monsoon (JJAS). The negative trend equivalent to that of CRU (-55.5) observation was predicted only by HQ16 (-55.8) while the other runs showed a positive trend.

Table 5. CRU observed and model simulated mean monthly rainfall $(\mathrm{mm})$ of Tamilnadu with trend (19712000).

\begin{tabular}{ccccccccccccccc}
\hline Models & Jan & Feb & Mar & Apr & May & Jun & Jul & Aug & Sep & Oct & Nov & Dec & Total & Trend \\
\hline CRU & 8 & 8 & 9 & 34 & 68 & 59 & 77 & 93 & 132 & 197 & 189 & 97 & 970 & -55.5 \\
HQ0 & 23 & 10 & 18 & 20 & 36 & 59 & 63 & 90 & 82 & 139 & 130 & 58 & 728 & 75.9 \\
HQ1 & 4 & 3 & 7 & 14 & 20 & 36 & 37 & 39 & 52 & 116 & 53 & 19 & 401 & 246 \\
HQ3 & 5 & 4 & 7 & 16 & 27 & 32 & 44 & 52 & 99 & 125 & 75 & 14 & 499 & 154.5 \\
HQ16 & 25 & 8 & 17 & 15 & 12 & 41 & 58 & 98 & 74 & 124 & 103 & 38 & 612 & -55.8 \\
REG & 35 & 13 & 17 & 32 & 77 & 201 & 181 & 179 & 144 & 136 & 137 & 76 & 1227 & 250.5 \\
\hline
\end{tabular}

The estimated error and index of agreement for rainfall simulation (Table 6) revealed that, except for REG (24mm monthly and $291 \mathrm{~mm}$ annual) all the PRECIS runs showed a negative bias for annual and monthly climatology indicating underestimation by these models. The correlation coefficient is significant and the annual RMSE ranged from 400 to $600 \mathrm{~mm}$. All models showed a better index of agreement for annual climatology compared to monthly climatology for rainfall. Only a low level of agreement was seen for rainfall in comparison with temperature climatology. 
Table 6. Error and agreement statistics for rainfall between model simulations and CRU observation (1971-2000).

\begin{tabular}{ccccccccc}
\hline \multirow{2}{*}{ Models } & \multicolumn{2}{c}{ Bias } & \multicolumn{2}{c}{ r2 } & \multicolumn{2}{c}{ RMSE } & \multicolumn{2}{c}{ d } \\
\cline { 2 - 10 } & Monthly & Annual & Monthly & Annual & Monthly & Annual & Monthly & Annual \\
\hline HQ0 & -14 & -172 & 0.21 & 0.29 & 74 & 403 & 0.46 & 0.59 \\
HQ1 & -45 & -540 & 0.80 & 0.27 & 76 & 601 & 0.45 & 0.40 \\
HQ3 & -36 & -434 & 0.17 & 0.22 & 72 & 514 & 0.46 & 0.45 \\
HQ16 & -26 & -316 & 0.22 & 0.24 & 72 & 438 & 0.46 & 0.50 \\
REG & 24 & 291 & 0.23 & 0.28 & 95 & 489 & 0.42 & 0.53 \\
\hline
\end{tabular}

\subsection{Uncertainty at the end of 21st century}

Decadal averages of weather parameters (solar radiation, maximum temperature, minimum temperature, relative humidity, wind speed and rainfall) were worked out to study the uncertainty in climate change projected at the end of the century.

\subsection{Solar radiation}

Solar radiation had both positive and negative deviation for Tamilnadu. In all the members studied (Table 7) the minimum variations in solar radiation ranged from -1.3 to $-0.2 \mathrm{MJm}-2$ and the maximum variation ranged from 0.1 to $0.9 \mathrm{MJm}-2$. On an average, the member HQ3 had no deviation and HQO (0.1 MJm-2) had positive deviation, whereas HQ1 (-0.5 MJm-2), HQ16 (-0.7 MJm-2) and REG $(-0.5 \mathrm{MJm}-2)$ had negative deviations. Overall, the projections suggested that solar radiation is likely to vary between -1.3 to $0.9 \mathrm{MJm}$-2across different grids of Tamilnadu.

\subsection{Maximum temperature}

Maximum temperature was projected to increase for Tamilnadu. In all the members studied (Table 7) the lowest rise in maximum temperature was projected by HQ1 $\left(1.7^{\circ} \mathrm{C}\right)$ and the highest by $\mathrm{HQO}\left(3.7^{\circ} \mathrm{C}\right)$. Remaining members showed intermediate variations. On an average the positive deviations for all members in the ascending order was from HQ1 $\left(2.2^{\circ} \mathrm{C}\right), \operatorname{REG}\left(2.7^{\circ} \mathrm{C}\right), \mathrm{HQ} 3\left(3.0^{\circ} \mathrm{C}\right), \mathrm{HQ} 16\left(3.0^{\circ} \mathrm{C}\right)$ and $\mathrm{HQO}$ $\left(3.4^{\circ} \mathrm{C}\right)$. The maximum temperature increment is likely to vary between 1.7 to $3.7^{\circ} \mathrm{C}$ considering all the projected members.

\subsection{Minimum temperature}

Minimum temperature was also projected to increase for Tamilnadu. In all the members studied (Table 7) the lowest minimum temperature was projected by $\mathrm{HQ} 1\left(1.9^{\circ} \mathrm{C}\right)$ and the highest by $\mathrm{HQ16}\left(4.3^{\circ} \mathrm{C}\right)$. On an average the positive deviations for all members in the ascending order is HQ1 $\left(2.6^{\circ} \mathrm{C}\right), \operatorname{REG}\left(3.2^{\circ} \mathrm{C}\right)$, HQ3 $\left(3.2^{\circ} \mathrm{C}\right), \mathrm{HQO}\left(3.7^{\circ} \mathrm{C}\right)$ and $\mathrm{HQ} 16\left(3.9^{\circ} \mathrm{C}\right)$. The overall performance suggested that the minimum temperature rise is likely to vary between 1.9 to $4.3^{\circ} \mathrm{C}$.

\subsection{Relative humidity}

Relative humidity had both positive and negative deviations for Tamilnadu. The minimum variations in relative humidity (Table 7) ranged from -3.0 to -0.6 per cent across the members studied. The maximum variation ranged from 0.0 to 2.2 per cent. On an average the members HQ16 ( 0.7 per cent) and REG ( 0.3 per cent) had positive deviations, while HQ0 (-1.9 per cent), HQ1 (-0.2 per cent) and HQ3 (-2.1 per cent) had negative deviations. The overall performance of projections suggested that relative humidity is likely to vary between -3.0 to 2.2 per cent.

\subsection{Wind speed}

Wind speed had both positive and negative deviations for Tamilnadu as has been observed with relative humidity. Among the members studied (Table 7), the minimum variations in wind speed ranged from -0.4 to $-0.1 \mathrm{kmh}-1$ across the members studied. The maximum variation ranged from 0.2 to $0.3 \mathrm{kmh}-1$. On an average three members HQO HQ1 and HQ3 projected positive deviations of $0.1 \mathrm{kmh}-1$, while HQ16 (-0.1 
kmph-1) and REG (-0.2 kmh-1) had negative deviations. Considering all the members the wind speed is expected to vary between -0.4 to $0.3 \mathrm{kmh}-1$.

\subsection{Rainfall}

Rainfall had both positive and negative deviations for Tamilnadu as is the case with relative humidity and wind speed. The minimum variations in rainfall (Table 7) ranged from -325 to $-63.6 \mathrm{~mm}$ across the members studied. The maximum variation ranged from 290 to $784.1 \mathrm{~mm}$. On an average the members HQ16 $(22.8 \mathrm{~mm})$ and REG $(162.7 \mathrm{~mm})$ projected positive deviations while HQ0 (-0.6 mm), HQ1 (-1.8 mm) and HQ3 $(-32.3 \mathrm{~mm})$ projected negative deviations.

Table 7. Uncertainty in climate projection over Tamilnadu at the end of 21st century.

\begin{tabular}{|c|c|c|c|c|}
\hline Weather parameters & Models & Minimum & Maximum & Average \\
\hline \multirow{5}{*}{ Solar radiation (MJm-2) } & HQO & -0.2 & 0.9 & 0.1 \\
\hline & HQ1 & 1.1 & 0.1 & -0.5 \\
\hline & HQ3 & -0.5 & 0.6 & 0.0 \\
\hline & HQ16 & -1.3 & 0.2 & -0.7 \\
\hline & REG & -0.8 & 0.4 & -0.5 \\
\hline \multirow{5}{*}{ Maximum temperature $\left({ }^{\circ} \mathrm{C}\right)$} & HQO & 2.8 & 3.7 & 3.4 \\
\hline & HQ1 & 1.7 & 2.5 & 2.2 \\
\hline & HQ3 & 2.2 & 3.3 & 3.0 \\
\hline & HQ16 & 2.6 & 3.5 & 3.0 \\
\hline & REG & 2.5 & 3.5 & 2.7 \\
\hline \multirow{5}{*}{ Minimum temperature $\left({ }^{\circ} \mathrm{C}\right)$} & HQO & 3.0 & 4.0 & 3.7 \\
\hline & HQ1 & 1.9 & 2.9 & 2.6 \\
\hline & HQ3 & 2.5 & 3.5 & 3.2 \\
\hline & HQ16 & 3.0 & 4.3 & 3.9 \\
\hline & REG & 3.0 & 3.3 & 3.2 \\
\hline \multirow{5}{*}{ Relative humidity (\%) } & HQO & -2.9 & 0.0 & -1.9 \\
\hline & HQ1 & -1.1 & 1.6 & -0.2 \\
\hline & HQ3 & -3.0 & 0.7 & -2.1 \\
\hline & HQ16 & -0.6 & 2.2 & 0.7 \\
\hline & REG & -0.8 & 0.9 & 0.3 \\
\hline \multirow{5}{*}{ Wind speed (Kmph) } & HQO & -0.1 & 0.2 & 0.1 \\
\hline & HQ1 & -0.3 & 0.3 & 0.1 \\
\hline & HQ3 & -0.2 & 0.2 & 0.1 \\
\hline & HQ16 & -0.3 & 0.2 & -0.1 \\
\hline & REG & -0.4 & 0.2 & -0.2 \\
\hline \multirow{5}{*}{ Rainfall (mm) } & HQO & -220.4 & 290.0 & -0.6 \\
\hline & HQ1 & -63.6 & 621.6 & -1.8 \\
\hline & HQ3 & -132.4 & 459.4 & -32.3 \\
\hline & HQ16 & -325.0 & 784.1 & 22.8 \\
\hline & REG & -171.0 & 392.9 & 162.7 \\
\hline
\end{tabular}

\subsection{Spatial variability}

Spatial variability was analysed for three weather parameters viz., maximum temperature, minimum temperature and rainfall as they exhibited definite differences compared to other weather parameters. Spatial pattern of projected maximum temperature (Fig. 4a, 4b) and minimum temperature (Fig. 5a, 5b) showed an increasing trend over Tamilnadu. The movement of increase in temperature gradient was from 
east to westie, from the east coast of study location to its inland areas. The spatial pattern of projected rainfall (Fig.6a, 6b) exhibited no definite trend in both the models over Tamilnadu except for the southern tip (Kanyakumari, which falls under the high rainfall zone of Tamilnadu), western pockets near the Western Ghats and northeastern tip and coastal areas.

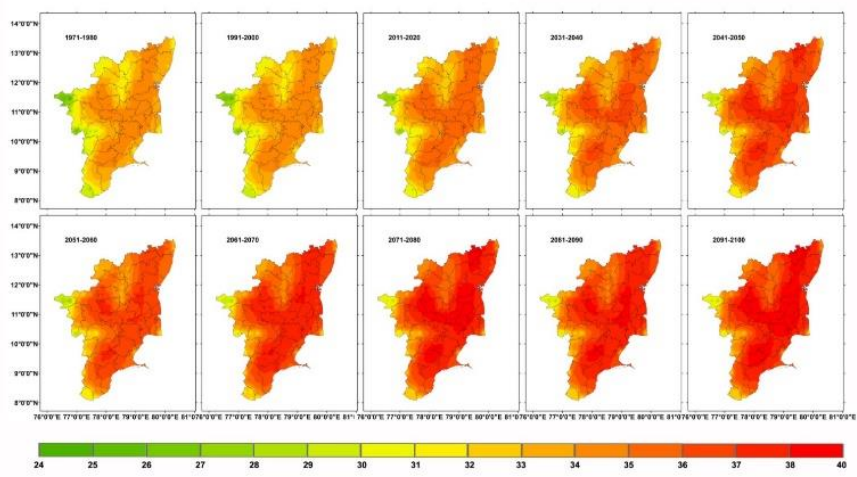

Figure 4a. Spatial pattern of maximum temperature $\left({ }^{\circ} \mathrm{C}\right)$ as projected by $\mathrm{HQO}$

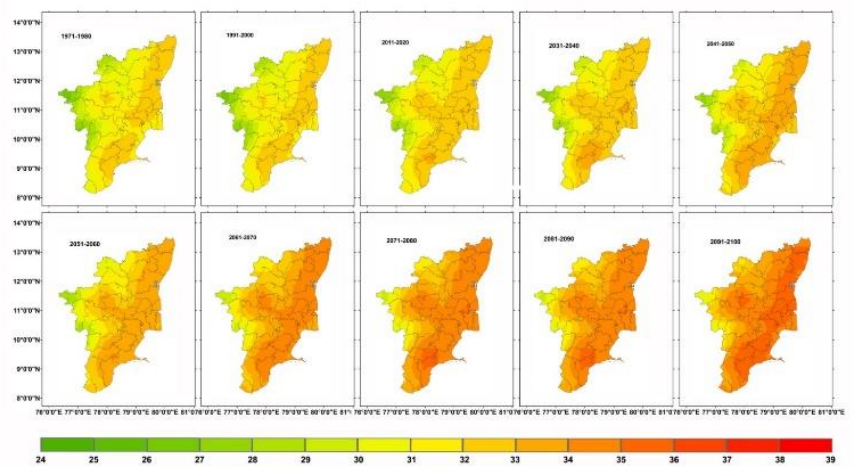

Figure $\mathbf{4 b}$. Spatial pattern of maximum temperature $\left({ }^{\circ} \mathrm{C}\right)$ as projected by RegCM4

\section{Discussion}

Verification showed that there exists variation between seasons and model members due to their difference in the physics options. Among the members of PRECIS, HQO showed good agreement with that of CRU as shown in the result. In most of the cases PRECIS showed over estimation of temperature (Rivington et al., 2008) and REG showed under estimation (Rahman et al., 2007). In case of rainfall interannual variability was in better agreement when compared to that of monthly climatology as reported by Seth et al. (2007).

\subsection{Uncertainty in climate projection}

It is reaffirmed from the study that solar radiation had no definite increase or decrease from the baseline as projected by different members. The mean negative and positive deviation indicating the dimming and brightening are likely because of differences in the aerosol content of atmosphere and other factors. Similar observations are also made in different locations (Dutton et al., 1991; Gilgen et al., 1998; Stanhill and Cohen, 2001; Liepert, 2002; Wild et al., 2004, 2005). Solar brightening over the southern horn of India was also reported by Kambezidis et al., (2012).

The maximum temperature and minimum temperature over Tamilnadu is likely to increase as projected by all the members studied, which has been reported by Wiltshire et al., (2010). There exist difference in range of maximum temperature projected by different members which could be attributed to the model 
parameters employed in the respective GCM that might have reflected in RCM used here (Diallo et al., 2012). Similar kind of increased projection for India was also observed by Chaturvedi et al. (2012).

Relative humidity and wind speed over Tamilnadu was projected to vary both positively and negatively by all the members studied, the range of increase or decrease was not consistent and the difference was also meager. The reasons attributed for the variation in other parameters earlier, might be the reason for the variations in between members. Rainfall over the state was not consistently projected to either increase or decrease by the members. It is observed that each member has increase in rainfall over few grids and decrease in few other grids depending upon their topography.

\subsection{Spatial pattern}

Spatial pattern of projected maximum temperature (Fig. 4a, 4b) and minimum temperature (Fig. 5a, 5b) showed an increasing trend over Tamilnadu. The movement of temperature gradient from east to west indicates the influence of sea on its east and Western Ghats of Tamilnadu on its west. This is in agreement with Ramaraj et al. (2009). Maximum temperature increment was less over southern tip, western pockets near Western Ghats, which can be attributed to the presence of higher elevation (Karmalkar et al., 2008) and dense forest cover.

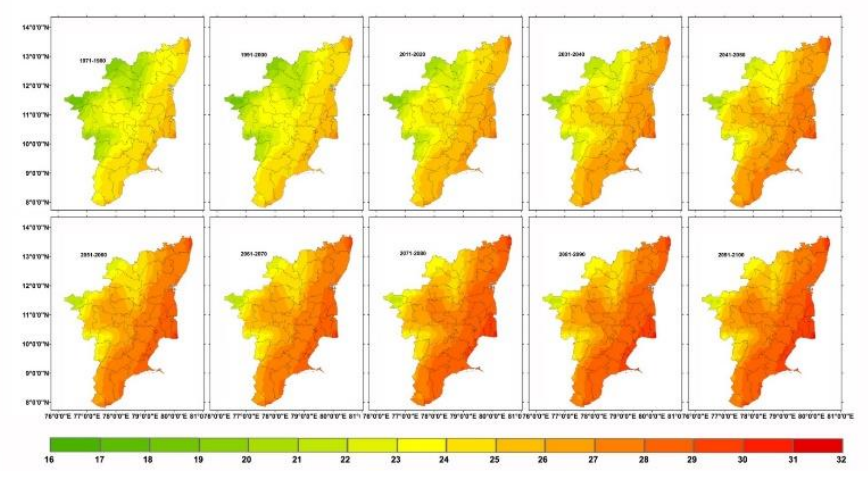

Figure 5a. Spatial pattern of minimum temperature $\left({ }^{\circ} \mathrm{C}\right)$ as projected by $\mathrm{HQO}$.

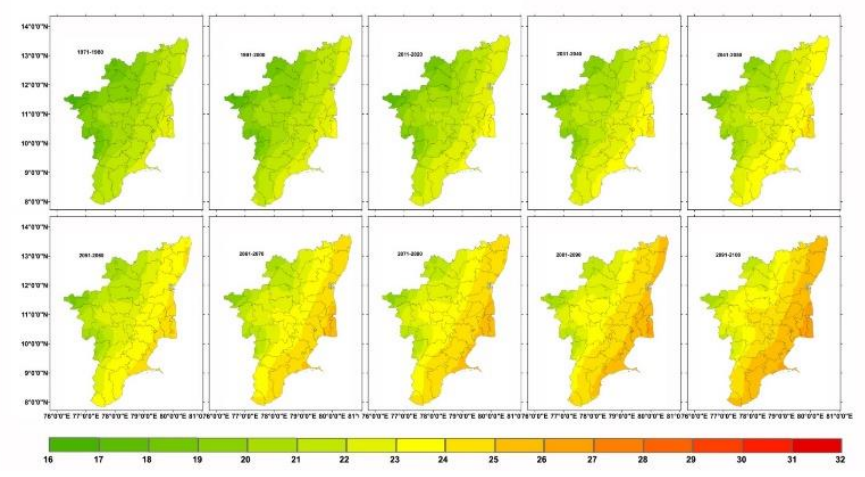

Figure $\mathbf{5 b}$. Spatial pattern of minimum temperature $\left({ }^{\circ} \mathrm{C}\right)$ as projected by RegCM4.

Spatial pattern of projected rainfall (Fig. 6a, 6b) exhibited definite increasing trend over the southern tip (Kanyakumari, which falls under the high rainfall zone of Tamilnadu), western pockets near the Western Ghats, northeastern tip and coastal areas by both the models. This might be due to the dense forest and high altitude in these regions. The increase in rate of precipitation was more in east coast in both the models and this could be due to cyclonic activity and changes in monsoon circulation that enhance moisture supply over Bay of Bengal which becomes conducive for deep convection and hence increased precipitation in the east coast as reported by Ashfaq et al., (2009). The increase in rainfall near the coast 
might also happen due to increased temperature near the coasts, which increases the evaporation and intensifies the hydrological cycle near the sea (Ramanathan et al., 2001).

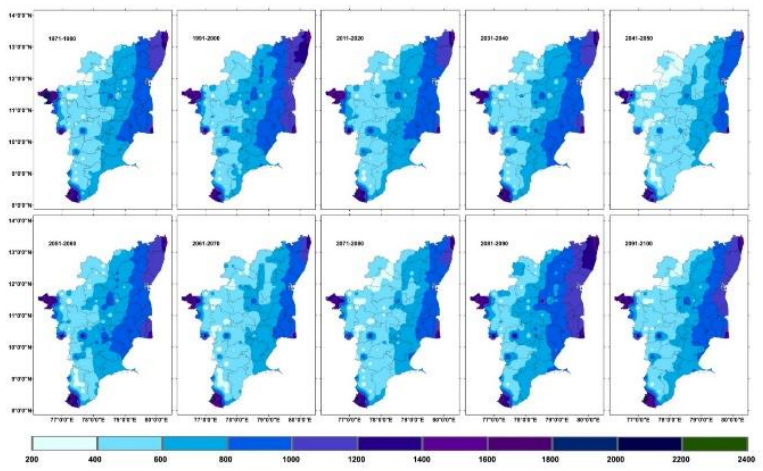

Figure 6a. Spatial pattern of rainfall $(\mathrm{mm})$ as projected by HQO

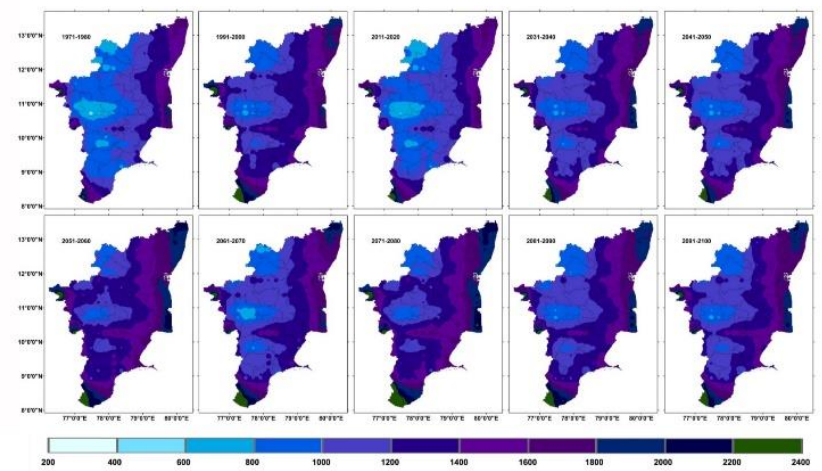

Figure $\mathbf{6 b}$. Spatial pattern of rainfall $(\mathrm{mm})$ as projected by RegCM4

\section{Conclusion}

From the study it was concluded that there exist wide range of uncertainty in maximum temperature, minimum temperature and rainfall. In case of solar radiation, relative humidity and wind speed no definite increase or decrease was projected and the difference was meager compared to base period. Spatial pattern of maximum temperature and minimum temperature showed temperature increment from east to west over the state. Rainfall showed increment in certain pockets of the state that covered hilly terrains and dense forests.

\section{Acknowledgement}

Authors are thankful to Hadley Centre, UK Met office for providing boundary conditions for the study and the Ministry of Foreign Affairs, Norway and the Royal Norwegian Embassy, New Delhi for their financial support to undertake the study through ClimaRice project.

\section{References}

Ashfaq M., Ying S., Wen-wen T., Trapp R.J., Xueijie G., Pal J.S. and Diffenbaugh N.S. (2009), Suppression of south Asian summer monsoon precipitation in the 21stcentury, Geophys. Res. Lett., 36(1), L01704. DOI: 10.1029/2008GL036500.

Chaturvedi R.K., Joshi J., Jayaraman M., Bala G. and Ravindranath N.H. (2012), Multi-model climate change projections for India under representative concentration pathways, Curr Sci., 103(7), 791-802. 
Cubasch U., Meehl G.A., Boer G.J., Stouffer R.J., Dix M., Noda A., Senior C.A., Raper S. and Yap K.S. (2001), Climate change 2001: the scientific basis. In Contribution of working group Ito the third assessment report of the Intergovernmental Panel on Climate Change (eds Houghton J.T., Ding Y., Griggs D. J., Noguer M., van der Linden P.J., Dai X., Maskell K. and Johnsen C.A.). Projections of future climate change, Chapter - 9, Cambridge, UK: Cambridge University Press, 525-582.

Diallo I., Sylla M.B., Giorgi F., Gaye A. T. and Camara M. (2012), Multimodel GCM-RCM Ensemble-Based Projections of Temperature and Precipitation over West Africa for the Early 21st Century, Int. J. Geophys, Article ID 972896, 19 pages doi:10.1155/2012/972896.

Dutton E.G., Stone R.S., Nelson D.W. and Mendonca B.G. (1991), Recent inter annual variations in solar radiation, cloudiness, and surface temperature at the South Pole, J. Clim., 4,848-858.

Gilgen H., Wild M. and Ohmura A. (1998), Means and trends of short wave irradiance at the surface estimated from Global Energy Balance Archive Data, J. Clim., 11, 2042-2061.

Kambezidis H.D., Kaskaoutis D.G., Shailesh Kumar K., Krishna Moorthy K., Satheeshe S.K., Kalapureddy M.C.R., Badarinath K.V.S., Rani Sharma A. and Wild M. (2012), Multi-decadal variation of the net downward shortwave radiation over south Asia: The solar dimming effect, Atmos. Environ., 50, 360-372.

Karmalkar A.V., Taylor M.A., Campbell J., Stephenson T., New M., Centella A., Benzanilla A. and Charlery J. (2013), A review of observed and projected changes in climate for the islands in the Caribbean, Atmosfera., 26(2),283309.

Liepert B.G. (2002), Observed reductions of surface solar radiation at sites in the United States and worldwide from 1961 to 1990, Geophys. Res. Lett., 29(10), 1421.

Rahman Md., Mizanur Md., Nazrul Islam, Ahsan Uddin Ahmed and Romee Afroz (2007), Comparison of RegCM3 simulated meteorological parameters in Bangladesh: Part II-preliminary result for temperature Institute of Physics - Sri Lanka, Sri Lankan Journal of Physics, 8, 11-19.

Ramanathan V., Crutzen P.J., Kiehl J.T. and Rosenfeld D. (2001), Aerosols, Climate and the Hydrological Cycle. Sci., 294, 2119-2124.

Ramaraj A.P., Jagannathan R. and Dheebakaran Ga. (2009), Impact of Climate Change on Rice And Groundnut Yield Using PRECIS Regional Climate Model And DSSAT Crop Simulation Model. ISPRS Archives XXXVIII-8/W3 Workshop Proceedings: Impact of Climate Change on Agriculture, 143-146.

Rivington M., Miller D., Matthews K.B., Russell G., Bellocchi G. and Buchan K. (2008), Evaluating regional climate model estimates against site-specific observed data in the UK., Climatic Change, 88, 157-185.

Schneider H.S and Duriseti K.K. (2002), Uncertainty and Climate Change Policy: A Survey, Island Press, Washington D.C., Chapter-2, 53-87.

Seth A., Sara E., Rauscher A., Suzana E., Camargo J., Jian-Hua Qian E. and Pal J.S. (2007), RegCM3 regional climatologies for South America using re-analysis and ECHAM global model driving fields, Clim Dyn., 28, 461-480.

Smith E. (2002), Uncertainty analysis. Edited by Abdel H. El-Shaarawi and Walter W. Piegorsch, Encyclopedia of Environmetrics, 4, 2283-2297.

Stanhill G. and Cohen S. (2001), Global dimming: A review of the evidence for a widespread and significant reduction in global radiation with discussion of its probable causes and possible agricultural consequences, Agric. For. Meteorol., 107,255-278.

Wild M., Ohmura A., Gilgen H. and Rosenfeld D. (2004), On the consistency of trends in radiation and temperature records and implications for the global hydrological cycle, Geophys. Res. Lett., 31, L11201, doi:10.1029/2003GLO 19188.

Wild M., Gilgen H., Roesch A., Ohmura A., Long C.N., Dutton E.G., Forgan B., Kallis A., Russak V. and Tsvetkov A. (2005), From dimming to brightening: Decadal changes in surface solar radiation, Sci., 308, 847-850.

Wiltshire A., Camilla M., Ridley J., Witham C., McSweeny C., Kumar P. and Jacob D. (2010), Analysis of Climate Uncertainty. High Noon Delivery Report Project No 227087, 1-31. 